\title{
Single-Pedicled Myocutaneous Flap of the Nose: A Case Study with Scar Quality Assessment
}

\author{
Christine Schopper ${ }^{\S}$, Eva Maria Valesky ${ }^{\S}$, Roland Kaufmann and Markus Meissner
}

\author{
Department of Dermatology, Venereology und Allergology, Johann Wolfgang Goethe-University, Frankfurt am Main, \\ Germany
}

\begin{abstract}
The plastic reconstruction of the nose after microscopically controlled tumor surgery poses a particular challenge. The single pedicled nasalis myocutaneous flap is suited for the repair of defects of the distal nose. The flap is characterized by great tissue mobility and ensured vascular supply. Below a case study is presented that involves 4 patients who were treated with this special flap in our hospital after excision of a basal cell carcinoma. The scar quality was measured after one year with the scar assessment tool POSAS (The Patient and Observer Scar Assessment Scale). The single pedicled nasalis myocutaneous flap healed without any complication in all 4 patients. The nose shape could be preserved by the almost tension-free shift of the flap on the myocutaneous pedicle. The evaluation with the POSAS showed good results for all individual parameters and in the overall assessment. The single pedicled nasalis myocutaneous flap offers a good alternative to repair defects on the distal nasal bridge, nasal ala and the nasal tip. The pedicle provides a maximum on mobility combined with a good perfusion of the flap. As the flap is built out of nose tissue the color and texture can be kept which leads to an excellent cosmetic result. The good results are also reflected by the evaluation of the POSAS data.
\end{abstract}

Keywords: Myocutaneous, pedicled flap, POSAS, scar, skin flap.

\section{INTRODUCTION}

The closure of nasal defects is a particular challenge due to the special anatomical conditions of the nose, which limits the ability to shift tissue. Cosmetic considerations also play a decisive role in this process, due to the central position and visibility of the nose. In principle, such defects can be closed by full-thickness skin grafts or local skin flaps. Fullthickness skin grafts may be distinguishable from surrounding tissue, due to primarily differences in surface structure and color, and they also tend to shrink. Skin flaps thus produce superior cosmetic results and are preferred to free transplants.

Frequently used local flap techniques that are particularly suitable for the coverage of defects on the ala and lateral tip of the nose include the nasolabial transposition or bilobed flap. As an alternative, subcutaneous island pedicle flaps are suitable for the closure of defects at the distal bridge, ala nasi, or tip of the nose, but they are characterized by limited mobilization capability in most cases. The single-pedicled myocutaneous flap is a nasal flap variant with good mobilization ability that provides a safe blood supply through the arteria angularis nasi. Rybka [1] first described the use of a myocutaneous island pedicle flap to cover nasal defects in 1983, and several authors have subsequently

*Address correspondence to this author at the Department of Dermatology, Venereology und Allergology, Johann Wolfgang Goethe-University, Theodor-Stern-Kai 7, D-60590 Frankfurt/Main, Germany; Tel: +49 69 6301-6845; Fax: +4969 6301-5403; E-mail: markus.meissner@kgu.de

${ }^{\S}$ Both authors contributed equally. described the application of a modified form of this flap [14]. In this article, we describe the use of the single-pedicled nasalis myocutaneous flap in a case series of four patients. We also report the first evaluation of flap and scar quality using the Patient and Observer Scar Assessment Scale (POSAS) [5-7].

\section{METHODS}

\section{Patients}

Between August 2011 and August 2012, four patients (two women, two men; age, 77-91 years) with sclerodermiforme basal cell carcinoma at the distal bridge of the nose were treated with this flap in our ward. Tumor excision was controlled by micrographic surgery in all cases. Defect size ranged from $1.3 \mathrm{~cm}$ to $1.8 \mathrm{~cm}$.

\section{Technique}

To create the single-pedicled nasalis myocutaneous flap, the triangular flap is first defined above the defect (Fig. 1a). An incision is made to the depth of adipose tissue to define the lateral side of the triangle, which is then mobilized laterally and subcutaneously above the musculus transversalis to the sulcus nasofaciale (Fig. 1b). On this side, the muscle remains intact and serves as a subcutaneous flap pedicle. At the medial flap margin, an incision is then made to the depth of the nasal cartilage or bone, through the musculus transversalis nasi. The flap is then released from the nasal cartilage below the musculature (Fig.1c). This bilayer (above and below the muscle) subcutaneous mobilization, which Papadopoulos et al. referred to as 


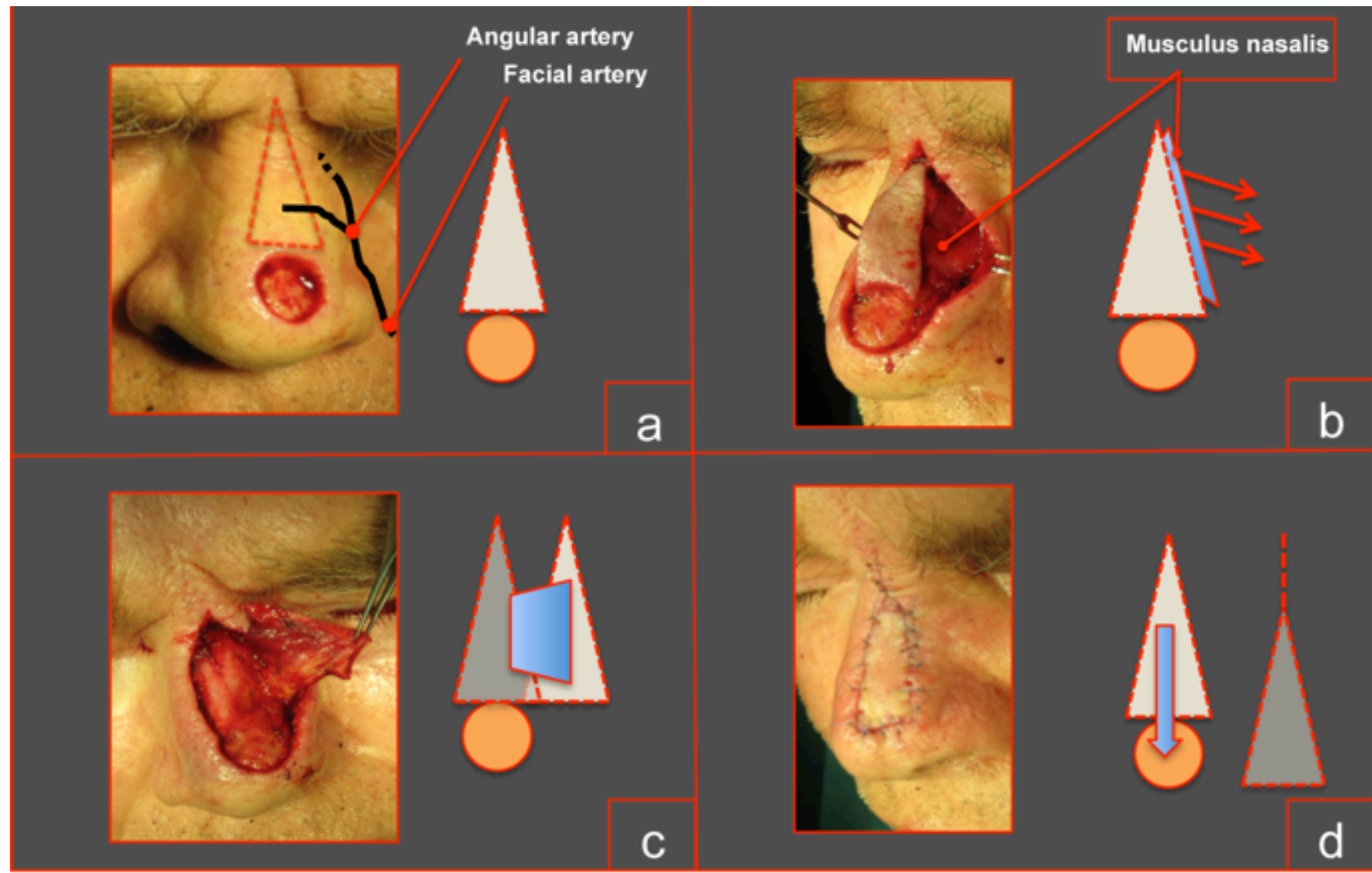

Fig. (1). (a) Triangular incision above the defect; (b) Mobilization lateral and subcutaneously above the musculus transversalis; (c) Release of the muscle from the nasal cartilage below the musculature; (d) Transfer to the defect without tension using its pedicle, and closure of the donor area in a V-Y shape.

"bilevel undermining" of the "nasalis myocutaneous island pedicle flap" generates great flap mobility [3].

The flap is then transferred to the defect without tension using its pedicle, and the donor area is closed in a V-Y shape (Fig. 1d). Blood supply to the flap is guaranteed by the circulation of the musculus transversalis nasi through the arteria angularis nasi.

\section{RESULTS}

Flaps were vital after $24 \mathrm{~h}$ and subsequently healed with no complication and good cosmetic results in all patients. Fig. (2) shows the initial defects and postoperative results after 1 year.

After 1 year, scar quality was evaluated as part of regular follow-up care using the POSAS, which consists of two parts: the patient and observer scales. Each scale is used to evaluate six parameters (e.g., scar color) using a 10-point scale (1:best result; 10: worst result) and obtain a summarizing judgment (Tables $\mathbf{1}$ and 2). The observer scale also allows the description of deviations, such as whether the scar is thinner or thicker than normal skin. Several survey studies have determined that the POSAS is a suitable means of evaluating scars [5-7]. Summary patient and observer scale scores (summarizers: C.S., E.V., M.M.) for the four patients in this case series are presented in Tables $\mathbf{1}$ and $\mathbf{2}$, respectively. Scores for all patient scale parameters were very good (1-2), indicating that patients were satisfied with scar quality. In contrast, observer scale scores ranged from 2 to 5 , indicating that surgeons classified scar quality as satisfactory to good. In particular, differences in relief and pigmentation were regarded as problematic.

\section{DISCUSSION}

The single-pedicled nasalis myocutaneous flap offers an alternative for the closure of defects of the lower bridge, ala nasi, and tip of the nose. The myocutaneous pedicle of the flap provides maximum mobility and a good blood supply via the arteria angularis nasi. Thus, lifting of the tip of the nose can be prevented. As the flap is generated from nose tissue, color and texture are preserved, producing a good cosmetic result. The disadvantages of this flap include its geometric shape, which results in a more conspicuous contour than that of a bilobed flap. This disadvantage is partially compensated by the excellent vascularization and great mobilization capability. The perfect vascularisation is assured by the arteria angularis nasi which originates not only from the facial arteria but also from the opthalmic arteria, infraorbital or transverse facial arteria [8]. In addition, the complex network between branches of the angular arteria and the dorsonasal artria might contribute to the good vascularisation of the musculus nasalis. 

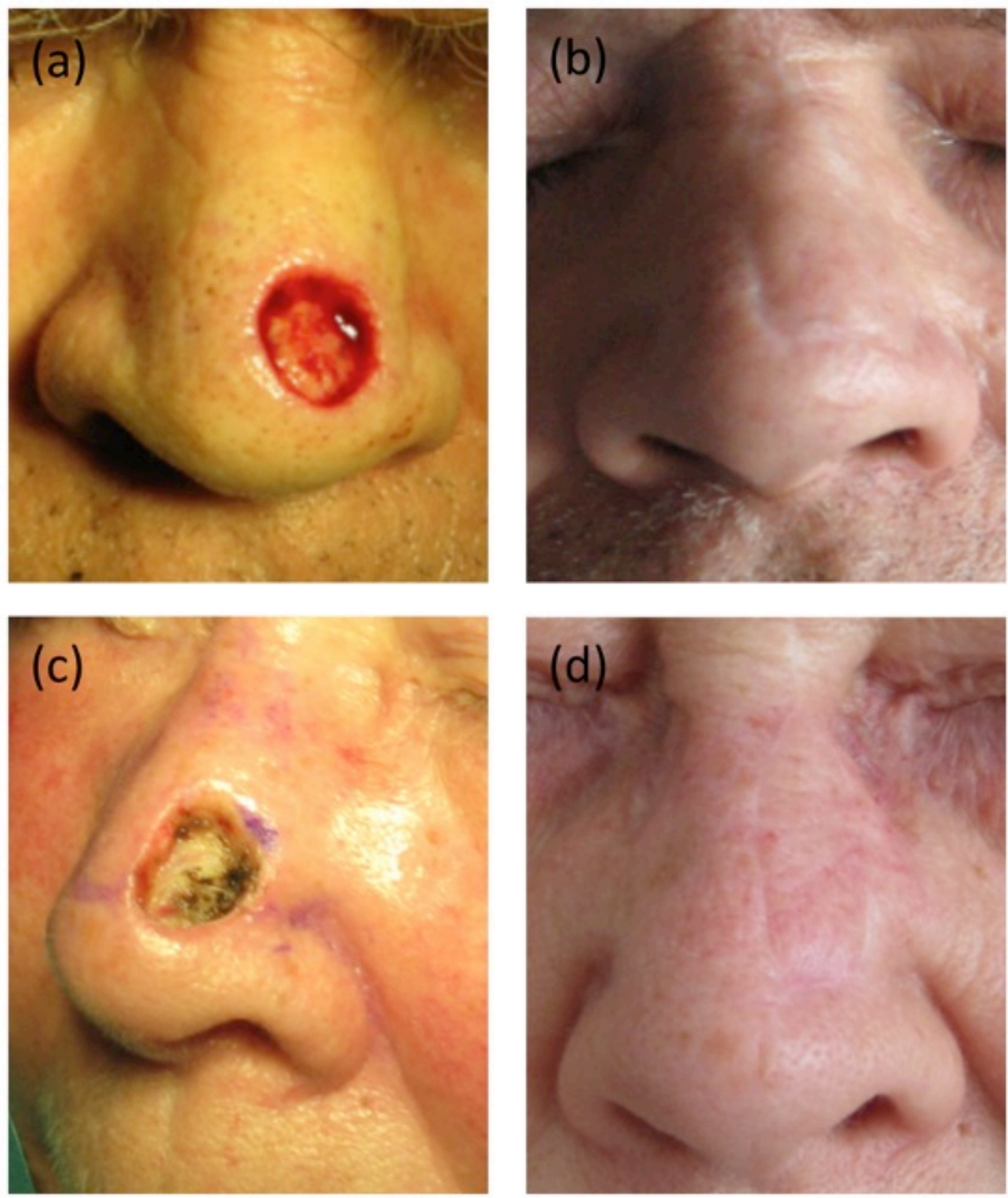

Fig. (2). Two examples of the single-pedicled nasalis myocutaneous flap. Primary defect (a, c) and postoperative results (b, d) after one year.

POSAS patient scale scores reflected great satisfaction in this small case series. The patient's evaluation indicated that scars were thinner than normal skin, with slight hypopigmentation compared with the surrounding skin. No hypertrophic scar or scar contraction was perceived. Overall patient scale scores ranged from 1 to 2 , indicating that patients perceived the flap as almost completely resembling normal skin.

Observer scale scores were generally lower than patient scale scores, indicating that surgeons had more critical appraisals of the cosmetic results of the surgery. Evaluators noted essential differences in relief and pigmentation.

Of course, comparison of the results of several different skin closure techniques using the POSAS would enable more objective assessment of the flap technique described here. This instrument is suitable for the assessment of flap and scar quality because it takes patients' perceptions into account, unlike other scales. This small case series provides only limited evidence, but it reveals some divergence in patients' and surgeons' evaluations of postoperative scar conditions following the use of the single-pedicled nasalis myocutaneous flap. Hence, the POSAS is also suitable for detecting differences between observers' and patients' perceptions. In summary, the described flap is nevertheless a very good option for the closure of nasal defects with good cosmetic outcome and high patient satisfaction. In the future, larger prospective studies should be performed to investigate whether this myocutaneous flap is superior or not to other ways of skin closure. 
Table 1. Results of the patient POSAS scale.

\begin{tabular}{|c|c|c|c|c|c|c|c|c|c|c|}
\hline \multirow{2}{*}{$N=4$} & \multicolumn{6}{|c|}{$1=n o$, not at all } & \multicolumn{4}{|c|}{ Yes, very much=10 } \\
\hline & 1 & 2 & 3 & 4 & 5 & 6 & 7 & 8 & 9 & 10 \\
\hline Has the scar been painful the last few weeks? & 4 & & & & & & & & & \\
\hline \multirow[t]{3}{*}{ Has the scar been itching the past few weeks? } & 4 & & & & & & & & & \\
\hline & \multicolumn{6}{|c|}{$1=$ no, as normal skin } & \multicolumn{4}{|c|}{ Yes, very different $=10$} \\
\hline & 1 & 2 & 3 & 4 & 5 & 6 & 7 & 8 & 9 & 10 \\
\hline $\begin{array}{l}\text { Is the scar color different from the color of your } \\
\text { normal skin at present? }\end{array}$ & 4 & & & & & & & & & \\
\hline $\begin{array}{l}\text { Is the stiffness of the scar differentfrom your normal } \\
\text { skin at present? }\end{array}$ & 3 & 1 & & & & & & & & \\
\hline $\begin{array}{l}\text { Is the thickness of the scar different from your normal } \\
\text { skin at present? }\end{array}$ & 4 & & & & & & & & & \\
\hline \multirow[t]{3}{*}{$\begin{array}{l}\text { Is the scar more irregular than your normal skin at } \\
\text { present? }\end{array}$} & 2 & 2 & & & & & & & & \\
\hline & \multicolumn{6}{|c|}{$1=a s$ normal skin } & \multicolumn{4}{|c|}{ Very different $=10$} \\
\hline & 1 & 2 & 3 & 4 & 5 & 6 & 7 & 8 & 9 & 10 \\
\hline $\begin{array}{l}\text { What is your overall opinion of the scar compared to } \\
\text { normal skin? }\end{array}$ & 2 & 2 & & & & & & & & \\
\hline
\end{tabular}

\section{CONFLICT OF INTEREST}

The authors confirm that this article content has no conflict of interest.

\section{ACKNOWLEDGEMENTS}

Declared none.

Table 2. Results of the observer POSAS scale as the mean value of the results of three different observers (dermatologic surgeons).

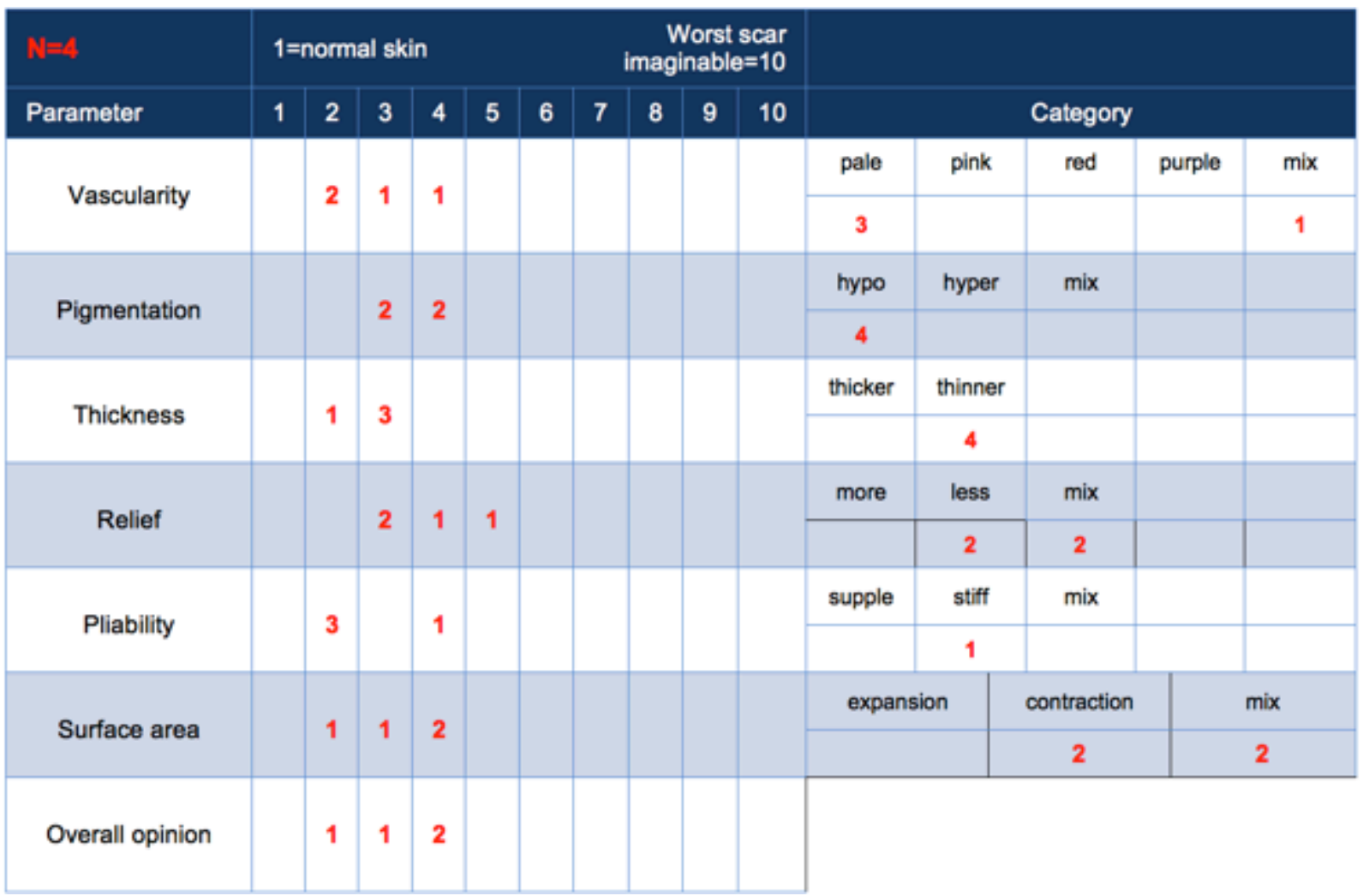




\section{REFERENCES}

[1] Rybka FJ. Reconstruction of the nasal tip using nasalis myocutaneous sliding flaps. Plast Reconstr Surg 1983; 71: 40-4.

[2] Constantine VS. Nasalis myocutaneous sliding flap: repair of nasal supratip defects. J Dermatol Surg Oncol 1991; 17(5): 439-44.

[3] Papadopoulos DJ, Trinei FA. Superiorly based nasalis myocutaneous island pedicle flap with bilevel undermining for nasal tip and supratip reconstruction. Dermatol Surg 1999; 25(7): 530-6.

[4] Wee SS, Hruza GJ, Mustoe TA. Refinements of nasalis myocutaneous flap. Ann Plast Surg 1990; 25(4): 271-8.
[5] Falder S, Browne A, Edgar D, et al. Core outcomes for adult burn survivors: a clinical overview. Burns 2009; 35(5): 618-41.

[6] Idriss N, Maibach $\mathrm{H}$. Scar assessment scales: a dermatologic overview. Skin Res Technol 2009; 15(1): 1-5.

[7] Vercelli S, Ferriero G, Sartorio F, Stissi V, Franchignoni F. How to assess postsurgical scars: a review of outcome measures. Disabil Rehabil 2009; 31(25): 2055-63.

[8] Hou D, Fang L, Zhao Z, Zhou C, Yang M. Angular vessels as a new vascular pedicle of an island nasal chondromucosal flap: Anatomical study and clinical application. Exp Ther Med 2013; 5(3): 751-6.

(C) Schopper et al.; Licensee Bentham Open.

This is an open access article licensed under the terms of the Creative Commons Attribution Non-Commercial License (http://creativecommons.org/licenses/by-nc/3.0/) which permits unrestricted, non-commercial use, distribution and reproduction in any medium, provided the work is properly cited. 